\title{
Association between blood eosinophils with exacerbation and patient-reported outcomes in chronic obstructive pulmonary disease patients in an endemic area for parasitic infections: a prospective study
}

\author{
Siwasak Juthong', Punchalee Kaenmuang ${ }^{2}$ \\ ${ }^{1}$ Division of Respiratory and Respiratory Critical Care Medicine, Department of Internal Medicine, Faculty of Medicine, Prince of Songkla \\ University, Songkhla, Thailand; ${ }^{2}$ Department of Internal Medicine, Faculty of Medicine, Prince of Songkla University, Songkhla, Thailand \\ Contributions: (I) Conception and design: P Kaenmuang, S Juthong; (II) Administrative support: All authors; (III) Provision of study materials or \\ patients: All authors; (IV) Collection and assembly of data: P Kaenmuang; (V) Data analysis and interpretation: S Juthong; (VI) Manuscript writing: \\ All authors; (VII) Final approval of manuscript: All authors. \\ Correspondence to: Siwasak Juthong, MD. Department of Internal Medicine, Faculty of Medicine, Prince of Songkla University, Hat Yai, Songkhla \\ 90110, Thailand. Email: jsiwasak@medicine.psu.ac.th; Punchalee Kaenmuang, MD. Department of Internal Medicine, Faculty of Medicine, Prince \\ of Songkla University, Hat Yai, Songkhla 90110, Thailand. Email: praeparry@gmail.com.
}

Background: Eosinophilic chronic obstructive pulmonary disease (COPD) patients have eosinophilic airway inflammation. No prospective study has reported blood eosinophil counts in an endemic area for parasitic infection. The primary objective was to compare exacerbation rates. The secondary objectives were patient-reported outcomes between eosinophilic and non-eosinophilic COPD.

Methods: A prospective study was conducted in COPD patients for 52 weeks. COPD was diagnosed according to GOLD criteria. Blood eosinophil counts were recorded at study entry. Exacerbations were recorded during the entire study period whereas COPD Assessment Test (CAT) and spirometry were recorded at 12 months. The eosinophilic and non-eosinophilic groups were defined by blood eosinophil counts $\geq 300$ and $<300$ cells/ $\mu \mathrm{L}$, respectively.

Results: A total of 145 COPD patients were included. Fifty-eight (40\%) and 87 (60\%) patients were eosinophilic and non-eosinophilic COPD and the median [interquartile range (IQR)] eosinophil counts were 481 [378.5, 675] and 149 [101.2, 208] cells/ $\mu \mathrm{L}$, respectively. The median (IQR) annual exacerbation rates were $3[2,4]$ and $2[2,2.5]$ times/year in the eosinophilic and non-eosinophilic groups, respectively $(\mathrm{P}=0.024)$. The eosinophilic group had higher admissions $(\mathrm{P}=0.007)$ but lower mortality $(\mathrm{P}=0.041)$. The patientreported outcomes were not statistically significantly different between the two groups. Eosinophil counts $\geq 300$ cells $/ \mu \mathrm{L}$ identified exacerbation in COPD patients with sensitivity and specificity of 0.71 and 0.64 , respectively.

Conclusions: COPD patients with blood eosinophil counts $\geq 300$ cells/ $\mu \mathrm{L}$ had more exacerbations and admissions but lower mortality than the non-eosinophilic patients. Blood eosinophil count is an effective biomarker to predict exacerbation risk in endemic parasitic areas.

Trial registration: NCT04123028 at ClinicalTrials.gov.

Keywords: Airway inflammation; chronic obstructive pulmonary disease (COPD); exacerbations; eosinophils; patient reported outcomes

Submitted Dec 26, 2019. Accepted for publication Jul 22, 2020.

doi: $10.21037 /$ jtd-19-4101

View this article at: http://dx.doi.org/10.21037/jtd-19-4101 


\section{Introduction}

Chronic obstructive pulmonary disease (COPD) is a common disease that is characterized by persistent respiratory symptoms and airflow limitation due to abnormalities of the airway or alveoli or both (1). From previous studies, about 10-40\% of COPD patients have eosinophilic airway inflammation during stable disease and exacerbations (2-4). These eosinophilic COPD patients respond well to corticosteroid therapy (5-8).

Recent studies showed that sputum eosinophils and blood eosinophils are good biomarkers for airway eosinophils to predict COPD exacerbation and clinical outcomes $(5-8)$. Horpers and colleagues $(9,10)$ found that eosinophilia (defined as an absolute blood eosinophil count $>275$ cells $/ \mu \mathrm{L}$ ) was associated with an increased risk of allcause mortality, and increased COPD-specific mortality [odds ratio 4.8; 95\% confidence interval (CI), 1.9-11.9]. A substantial number of studies have showed associations between an elevated blood eosinophil count or sputum eosinophil count and exacerbation rates or clinical outcomes of COPD patients. However, there are no reports of elevated blood eosinophil count or sputum eosinophil count in Thai COPD patients even though Thailand is a highly endemic area for parasitic infection which could interfere with the correlation of a high blood eosinophil count.

A sputum eosinophil count cannot be done in general practice so we used the blood eosinophil count as the biomarker. This research identified eosinophilic COPD patients with the primary objective of comparing the exacerbation rates in eosinophilic and non-eosinophilic COPD patients after a 12-month follow-up. The secondary objective was to describe the patient-reported outcomes between the eosinophilic and non-eosinophilic COPD patients.

\section{Methods}

\section{Study design}

A prospective cohort study was conducted in Songklanagarind Hospital, Thailand from December 2017 to December 2018. Eligible cases included stable COPD patients who came for follow-up at the outpatient department and were diagnosed as COPD according to the criteria described in the Global Initiative for Chronic Obstructive Lung disease (GOLD) guideline 2017 (11). The excluded participants were: (I) patients who had other conditions which could cause eosinophilia (12) \{i.e., known parasitic infection, allergy, asthma or asthma COPD overlap according to the Global Initiative for Asthma [2017] guideline (13), autoimmune disease, adrenal insufficiency, hematologic malignancy, or receiving medication which could cause eosinophilia\}; (II) patients who had previous acute exacerbation within 30 days before study entry; and (III) patients who had previous systemic corticosteroid therapy within 30 days before study entry. This study was conducted in accordance with the Declaration of Helsinki (as revised in 2013). This study was reviewed and approved by the Office of Human Research Ethics Committee at the Faculty of Medicine, Prince of Songkla University, Thailand (REC.60-319-14-3).

\section{Study objectives}

The primary objective of this study was to compare exacerbation rates in eosinophilic and non-eosinophilic COPD patients during a 12 -month follow-up. The secondary objective was to describe patient-reported outcomes between eosinophilic and non-eosinophilic COPD patients.

\section{Sample size}

The sample size was calculated using the application called n4Studies (14) for testing two independent proportions (two-tailed test). The proportions in the eosinophilic and non-eosinophilic groups were 0.370 and 0.130 , respectively, based on a previous study (15). The ratio was 1.50 , alpha was 0.05 , and beta was 0.20 . The sample sizes for the eosinophilic and non-eosinophilic groups were 58 and 87, respectively, for a total sample size of 145 which included an additional $20 \%$ for missing data.

\section{Patients}

All patients who were included in our study met the inclusion criteria and signed informed consent forms. At the screening period, stool specimens from each patient were collected three times and examined for parasites. Patients who had parasitic infections were excluded from the study. Complete blood counts were performed two times in all of the included patients and analyzed in a central laboratory at the time of study entry and 30 days after study entry to prevent variability. The means of the blood eosinophil counts were calculated and the patients were assigned into either the eosinophilic or non-eosinophilic COPD group. 


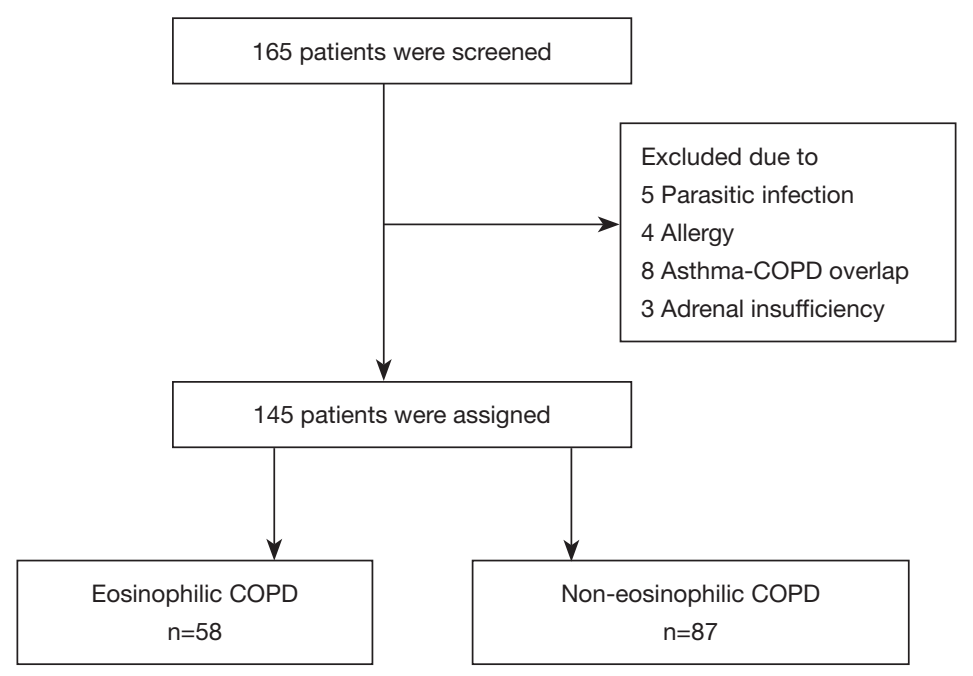

Figure 1 Patient flow diagram. COPD, chronic obstructive pulmonary disease.

Eosinophilic and non-eosinophilic COPD were defined as blood eosinophil counts at the time of study entry as $\geq 300$ and $<300$ cells $/ \mu \mathrm{L}$, respectively (16).

Baseline demographics and characteristics of all patients, including COPD GOLD assessment group, GOLD airflow limitation severity, smoking status, body mass index, modified Medical Research Council (mMRC) dyspnea score, and exacerbation rate in the previous year, were collected by the original investigator at the baseline visit. An exacerbation of COPD was defined by a new onset of two or more events of dyspnea, coughing, increased sputum production or chest tightness that led to a change in treatment with systemic glucocorticoids or antibiotics for at least 3 days (11). The severity of the exacerbation of COPD was classified as mild (which required an increased dosage of a short acting beta-2-agonist), moderate (which led to a visit to an emergency department), and severe (which led to hospitalization). The exacerbation rates were recorded during the entire study period, whereas all patient symptoms, COPD Assessment Test (CAT) score, spirometry results, hospitalization, lengths of hospital stay, and mortality were collected at the scheduled visit of 12 months. All patients were also followed up as scheduled with their primary doctors.

\section{Statistical analysis}

Descriptive data are presented as mean $\pm \mathrm{SD}$, median (IQR), and number with percent (\%) based on the type of data. Continuous data are presented as mean \pm SD or median
(IQR), difference in data used the t-test whereas categorical data are presented as number and percentage. Differences in data used the chi-square test and Fisher's exact test. COPD exacerbation rates were compared by Fisher's exact test. The rank-sum test was used to demonstrate the relationship between the blood eosinophil counts and exacerbation rates. The predicting factors were determined by multivariate logistic regression (adjusted for age, sex, BMI, smoking, $\mathrm{FEV}_{1}, \mathrm{mMRC}$ ) and presented with adjusted odd ratios. We also determined a receiver operating characteristic curve (ROC) analysis to evaluate the optimal cut-off value of blood eosinophil count. The statistical analysis used the $\mathrm{R}$ 3.5.2 software and the results were considered statistically significant if the $\mathrm{P}$ value was $<0.05$.

\section{Results}

One hundred and sixty-five COPD patients were screened and a total of 145 patients were assigned into the two groups based on the blood eosinophil counts. Fiftyeight $(40 \%)$ and $87(60 \%)$ patients were assigned to the eosinophilic and non-eosinophilic groups, respectively (Figure 1). Demographic and clinical characteristics at the time of study entry are presented in Table 1. One hundred and thirty-seven $(94.5 \%)$ patients were men and the mean age was $73.9 \pm 9.7$ years old. The mean post-bronchodilator $\mathrm{FEV}_{1}$ (\% of predicted) was $53.1 \pm 11.8$ and the median annualized exacerbation rate in the previous year before study entry, was 1 time per year $(\mathrm{P}=0.239)$. There were no differences in the baseline characteristics between the two 
Table 1 Demographic and clinical characteristics at baseline

\begin{tabular}{|c|c|c|c|c|}
\hline Characteristic & Total $(n=145)$ & $\begin{array}{l}\text { Eosinophilic COPD } \\
\qquad(n=58)\end{array}$ & $\begin{array}{l}\text { Non-eosinophilic COPD } \\
\qquad(\mathrm{n}=87)\end{array}$ & $P$ value \\
\hline Male, n (\%) & $137(94.5)$ & $56(96.6)$ & $81(93.1)$ & $0.476^{\mathrm{C}}$ \\
\hline Smoking status, n (\%) & & & & $0.747^{\circ}$ \\
\hline Non-smokers & $5(3.4)$ & $1(1.7)$ & $4(4.6)$ & \\
\hline Pack-years, median [IQR] & $30[20,40]$ & $25[20,40]$ & $30[20,40]$ & $0.454^{\mathrm{e}}$ \\
\hline \multicolumn{5}{|l|}{ Comorbidities, n (\%) } \\
\hline Lung cancer & $2(1.4)$ & $2(2.3)$ & $0(0)$ & $0.428^{f}$ \\
\hline Pulmonary hypertension & $4(2.8)$ & $1(1.7)$ & $3(3.4)$ & $0.65^{f}$ \\
\hline Exacerbation rate in previous year, median (IQR) & $1(0,2)$ & $1(0,2)$ & $1(0,2)$ & $0.239^{\mathrm{e}}$ \\
\hline Body mass index $\left(\mathrm{kg} / \mathrm{m}^{2}\right)$, median (IQR) & $22.7(19.8,24.3)$ & $22.7(20.3,24.5)$ & $22.7(19.7,24.2)$ & $0.479^{\mathrm{e}}$ \\
\hline GOLD group, n (\%) & & & & $0.281^{f}$ \\
\hline$A$ & $20(13.8)$ & $7(12.1)$ & $13(14.9)$ & \\
\hline $\mathrm{B}$ & $49(33.8)$ & $15(25.9)$ & $34(39.1)$ & \\
\hline 1 & $41(28.3)$ & $19(32.8)$ & $22(25.3)$ & \\
\hline 2 & $73(50.3)$ & $25(43.1)$ & $48(55.2)$ & \\
\hline 3 & $29(20.0)$ & $14(24.1)$ & $15(17.2)$ & \\
\hline 4 & $1(0.7)$ & $0(0)$ & $1(1.1)$ & \\
\hline CAT score, mean \pm SD & $20.5 \pm 8.1$ & $18.7 \pm 8.9$ & $21.6 \pm 7.5$ & $0.142^{d}$ \\
\hline Post-bronchodilator $\mathrm{FEV}_{1}(\mathrm{~L})$, mean $\pm \mathrm{SD}$ & $1.4 \pm 0.5$ & $1.5 \pm 0.5$ & $1.4 \pm 0.5$ & $0.129^{\mathrm{e}}$ \\
\hline Post-bronchodilator $\mathrm{FEV}_{1}(\%$ of predicted), mean $\pm \mathrm{SD}$ & $53.1 \pm 11.8$ & $55.4 \pm 10.6$ & $51.6 \pm 12.5$ & $0.061^{\mathrm{e}}$ \\
\hline
\end{tabular}

Table 1 (continued) 
Table 1 (continued)

\begin{tabular}{|c|c|c|c|c|}
\hline Characteristic & Total $(n=145)$ & $\begin{array}{l}\text { Eosinophilic COPD } \\
\qquad(\mathrm{n}=58)\end{array}$ & $\begin{array}{l}\text { Non-eosinophilic COPD } \\
\qquad(\mathrm{n}=87)\end{array}$ & $P$ value \\
\hline \multicolumn{5}{|l|}{ Baseline inhaler use, n (\%) } \\
\hline ICS/LABA & $67(46.2)$ & $26(44.8)$ & $1(1.1)$ & $0.919^{f}$ \\
\hline ICS/LAMA/LABA & $61(42.1)$ & $23(39.7)$ & $38(43.7)$ & $0.706^{f}$ \\
\hline ICS dose ( $\mu \mathrm{g} /$ day), median [IQR] & $500[500,500]$ & $500[500,640]$ & $500[500,500]$ & $0.273^{\mathrm{e}}$ \\
\hline Absolute blood eosinophil count ( $\times 10^{9}$ cells $\left./ \mathrm{L}\right)$, median (IQR) & $242.5(129.5,421)$ & $481(378.5,675)$ & $149(101.2,208)$ & $<0.001^{\mathrm{e}}$ \\
\hline
\end{tabular}

The differences between groups $(\mathrm{P}<0.05)$ were calculated with ${ }^{\mathrm{c}}$, Fisher's exact test, ${ }^{\mathrm{d}}, t$-test, ${ }^{\mathrm{e}}$, rank-sum test, and ${ }^{\mathrm{f}}$, chi-square test. IQR, interquartile range; GOLD, Global Initiative for Chronic Obstructive Lung Disease; mMRC, Modified Medical Research Council; CAT, COPD Assessment Test; SD, standard deviation; $\mathrm{FEV}_{1}$ forced expiratory volume in 1 second; ICS, inhaled corticosteroid; LABA, long-acting $\beta 2$ agonist; LAMA, long-acting muscarinic antagonist. COPD, chronic obstructive pulmonary disease.

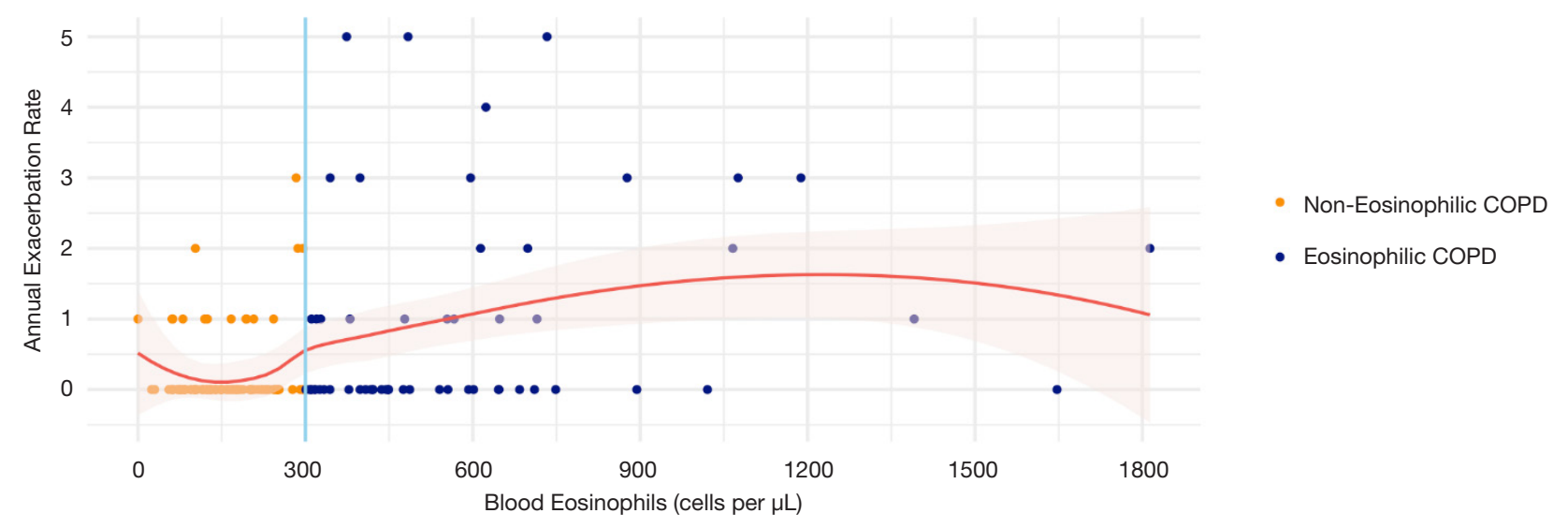

Figure 2 Association between blood eosinophils counts and exacerbation rate at 12 months. COPD, chronic obstructive pulmonary disease.

groups. The baseline median eosinophil count of all patients was $242.5 \times 10^{9}$ cells/L. The median eosinophil counts in the eosinophilic and non-eosinophilic COPD groups were 481 $(378.5,675)$ and $149(101.2,208) \times 10^{9}$ cells/L, respectively. At the follow-up time of 12 months, the eosinophilic COPD patients had higher exacerbation rates than the non-eosinophilic COPD patients (Figure 2). The median annual exacerbation rates were 3 and 2 times/year in the eosinophilic and non-eosinophilic groups, respectively. The exacerbation rate in the eosinophilic group was significantly higher $(\mathrm{P}=0.024)$ (Table 2).

The number of admissions within 12 months was significantly higher in the eosinophilic group compared to non-eosinophilic group $(\mathrm{P}=0.007)$. However, other clinical outcomes, such as length of hospital stay, or respiratory support by either non-invasive or invasive mechanical ventilation, were not statistically significantly different between the two groups (Table 2).

Other patient-reported outcomes such as mMRC dyspnea score, CAT score, and spirometry results after 12 months were not statistically significantly different between the two groups (Table 3). After the 12-month follow-up, higher mortality occurred in the noneosinophilic group $(\mathrm{P}=0.041)$ where three patients died 
Table 2 Exacerbation rate and admission data after 12-month follow-up

\begin{tabular}{|c|c|c|c|}
\hline End point & Eosinophilic COPD & Non-eosinophilic COPD & $P$ value \\
\hline No. of admission**, n (\%) & & & 0.007 \\
\hline 1 & $12(21.4)$ & $9(10.8)$ & \\
\hline 2 & $4(7.1)$ & $2(2.4)$ & \\
\hline No. of intubation rate ${ }^{\star \star}, \mathrm{n}(\%)$ & & & 0.229 \\
\hline 1 & $4(7.1)$ & $3(3.6)$ & \\
\hline 2 & $3(5.4)$ & $1(1.2)$ & \\
\hline Length of hospital stay, median (IQR) & $5.3(3.6-7.5)$ & $5.5(3-7.2)$ & 0.799 \\
\hline
\end{tabular}

*, analyzed by Ranksum test; **, analyzed by Fisher's exact test. COPD, chronic obstructive pulmonary disease; IQR, interquartile range.

Table 3 Patient-reported outcomes and spirometry after 12-month follow-up

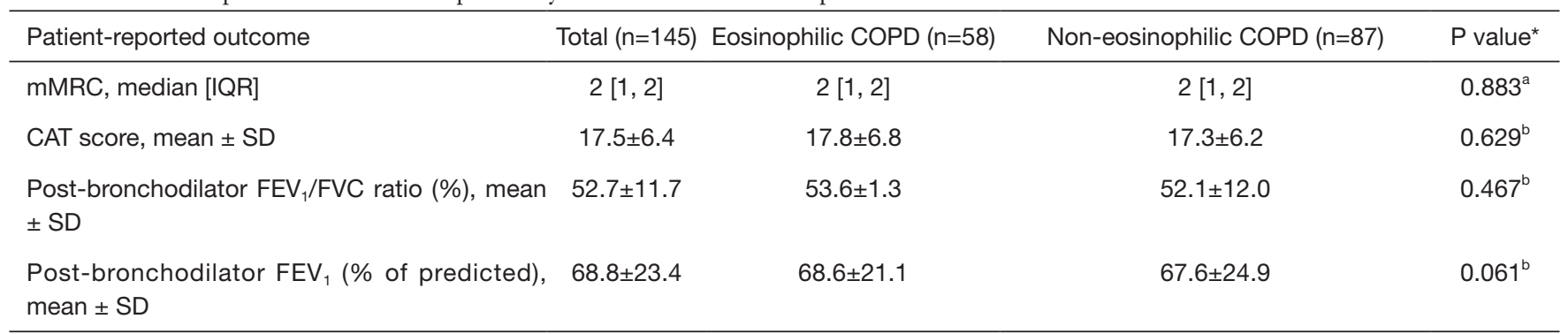

${ }^{*}$, the differences between groups $(\mathrm{P}<0.05)$ were calculated with the use of the ${ }^{\mathrm{a}}$, rank-sum test and ${ }^{\mathrm{b}}$, $t$-test. mMRC, Modified Medical Research Council; IQR, interquartile range; CAT, COPD Assessment Test. COPD, chronic obstructive pulmonary disease.

from pneumonia, acute myocardial infarction, and lung cancer. All of them received inhaled corticosteroid therapy whereas no deaths occurred in the eosinophilic group.

From a logistic regression analysis, we found that the blood eosinophil count and CAT score were the two significant predicting factors of COPD exacerbation with adjusted odds ratios of 3.91 and 1.11 , respectively. At study entry, we used a blood eosinophil cut-off point of $\geq 300$ cells $/ \mu \mathrm{L}$ to define eosinophilic COPD. We also found that a blood eosinophil count $\geq 300$ cells $/ \mu \mathrm{L}$ had a sensitivity of 0.71 and specificity of 0.64 [ROC 0.70 (95\% CI, 0.59-0.80)] for differentiating between eosinophilic and non-eosinophilic COPD patients (Figure 3).

\section{Discussion}

Our results found that in a highly endemic area for parasitic infection, a blood eosinophil count $\geq 300$ cells/ $\mu \mathrm{L}$ in COPD patients had more frequent exacerbations and a higher number of hospital admissions than the noneosinophilic patients. However, mortality was significantly higher in the non-eosinophilic COPD patients. There were no other differences in the patient-reported outcomes between the two groups except the number of admissions into the hospital. The blood eosinophil count and CAT score were significant predictive factors of COPD exacerbation with adjusted odds ratios of 3.91 and 1.11 , respectively.

This is the first study to identify an association between the blood eosinophil count and exacerbation rate in COPD patients in a highly endemic area for parasitic infection. Thailand and other countries in Southeast Asia are endemic areas for parasitic infections which could interfere with the usefulness of blood eosinophil counts as a biomarker to predict eosinophilic COPD patients. A previous study reported a prevalence of parasitic infection of $8.94 \%$ in 


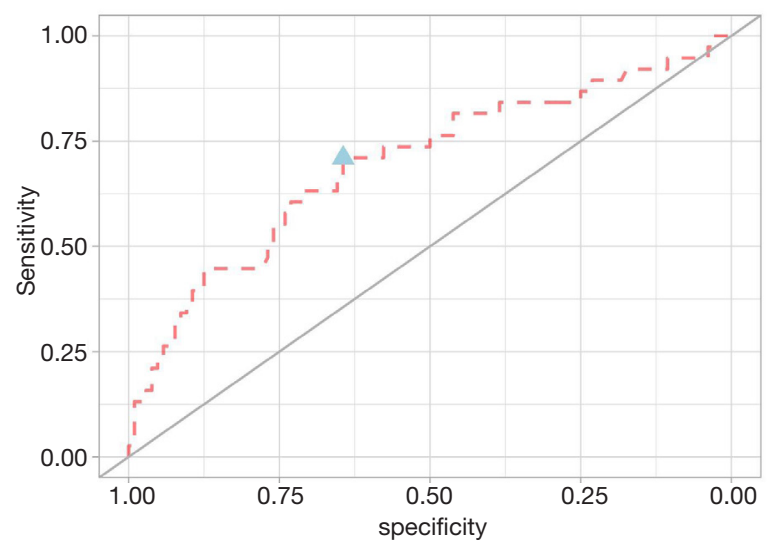

Figure 3 Receiver operating characteristic curve (ROC) curve for blood eosinophils $>300$ cells $/ \mu \mathrm{L}$ to differentiate eosinophilic COPD patients. COPD, chronic obstructive pulmonary disease.

Thailand (17), whereas this current study found a prevalence of $3.0 \%$. A decrease in the incidence of parasitic infections in Thai patients has occurred during the last 5-10 years which may reflect the improvement of hygiene in the Thai population (18). In our study we performed stool exams three times for parasites and also excluded other conditions that could cause eosinophilia. Our study results showed that the blood eosinophil counts can be a useful biomarker in a highly endemic area for parasitic infection COPD patients. Therefore, we suggest that Thai COPD patients with eosinophilia be screened for parasitic infection prior to stratification for COPD exacerbation risk.

In our study, COPD patients with high blood eosinophil counts had more exacerbations, more admissions, and lower mortality than the non-eosinophilic patients. Our hypothesis for the lower mortality was eosinophilic COPD patients are associated with increased corticosteroid responsiveness. Ho et al. (19) conducted a meta-analysis of outcome measures that compared eosinophilic and non-eosinophilic COPD patients. That study reported higher eosinophil counts in an outpatient sub-group which demonstrated increased risk of COPD exacerbation by $18 \%$. Couillard et al. (20) reported that eosinophilia in a Western country was associated with an increased risk of 12-month COPD-related readmission, 12-month all-cause readmission, and a shorter time to first COPD-related readmission. In this current study, however, the length of stay was not statistically different between the eosinophilic and non-eosinophilic patients. A previous study was conducted in an Asian population by Barnes et al. (21) Among the Japanese patients, the median (IQR) absolute eosinophil count was 170 cells $/ \mathrm{mm}^{3}\left(100-280\right.$ cells/mm $\left./ \mathrm{mm}^{3}\right)$ which was similar to non-Japanese patients. However, no difference was observed in the proportions of Japanese or non-Japanese patients with a prior history of COPD exacerbations between the $<2 \%$ and $\geq 2 \%$ eosinophil count subgroups, which was different from our study.

In this current study, we used a ROC curve to determine the best blood eosinophil count cut-off to predict exacerbations in COPD patients. We found that a blood eosinophil count $\geq 300$ cells $/ \mu \mathrm{L}$ had a sensitivity of 0.71 and specificity of 0.64 [area under the curve (AUC) 0.70]. This result was similar to the Copenhagen study (14), which also used the peripheral eosinophil count to predict exacerbations in stable COPD patients. The optimal blood eosinophil count cut-off points according to the ROC curves were 340 cells/ $\mu \mathrm{L}$ (AUC 0.63) and 3.3\% (AUC 0.59). The AUC value in our study was 0.70 but the sensitivity and specificity were not high. These results indicate that the blood eosinophil count has a fair overall accuracy to predict COPD exacerbation.

From the logistic regression analysis in our study, blood eosinophil levels $\geq 300$ cells $/ \mu \mathrm{L}$ were associated with a 3.39-fold increased risk of exacerbations. This was similar to the Copenhagen study (14) that reported that blood eosinophil levels $>340$ cells $/ \mu \mathrm{L}$ were associated with a 3.21 -fold increased risk of severe exacerbations. Furthermore, levels $>2 \%$ were associated with a 1.85 -fold increased risk of severe exacerbations. These results support the view that eosinophilic COPD patients have a higher risk of future exacerbations.

The strengths of our study were: (I) the prospective study design; (II) the first study in a highly endemic area for parasitic infection which could interfere with the correlation of a high blood eosinophil count in COPD patients; (III) follow-up period of 12 months; and (IV) other common causes of eosinophilia were excluded before enrollment. The limitation of this study was that most of the patients in this study were followed at the chest clinic where the patients were treated by pulmonology fellows and staff personnel. Therefore, the exacerbation rates per year might be lower than reported in other studies.

In conclusion, a blood eosinophil count equal to or greater than 300 cells $/ \mu \mathrm{L}$ can be an effective biomarker to predict exacerbation risk in COPD patients in a highly endemic area for parasitic infection. A larger number of patients and longer study duration of eosinophilic COPD should be done in the future to help guide the appropriate treatments in COPD patients. 


\section{Acknowledgments}

The authors are grateful to Nawaporn Assanagkornchai from the Critical Care Unit, Internal Medicine Department, Faculty of Medicine, Prince of Songkla University, and Nannapat Pruphetkaew from the Epidemiology Unit, Faculty of Medicine, Prince of Songkla University for the data analysis.

Funding: None.

\section{Footnote}

Data Sharing Statement: Available at http://dx.doi. org/10.21037/jtd-19-4101

Conflicts of Interest: All authors have completed the ICMJE uniform disclosure form (available at http://dx.doi. org/10.21037/jtd-19-4101). The authors have no conflicts of interest to declare.

Ethical Statement: The authors are accountable for all aspects of the work in ensuring that questions related to the accuracy or integrity of any part of the work are appropriately investigated and resolved. This study was conducted in accordance with the Declaration of Helsinki (as revised in 2013). This study was reviewed and approved by the Office of Human Research Ethics Committee at the Faculty of Medicine, Prince of Songkla University, Thailand (REC.60-319-14-3). All participants gave informed consent before participating into this study. The participants' personal data have been protected and secured.

Open Access Statement: This is an Open Access article distributed in accordance with the Creative Commons Attribution-NonCommercial-NoDerivs 4.0 International License (CC BY-NC-ND 4.0), which permits the noncommercial replication and distribution of the article with the strict proviso that no changes or edits are made and the original work is properly cited (including links to both the formal publication through the relevant DOI and the license). See: https://creativecommons.org/licenses/by-nc-nd/4.0/.

\section{References}

1. Lozana R, Naghavi M, Foreman K,et al. Global and regional mortality from 235 causes of death for 20 age groups in 1990 and 2010: a systemic analysis for the Global Burden of Disease Study 2010. Lancet 2012;380:2095-128.
2. Leigh R, Pizzichini MM, Morris MM, et al. Stable COPD: predicting benefit from high-dose inhaled corticosteroid treatment. Eur Respir J 2006;27:964-71.

3. Siva R, Green RH, Brightling CE, et al. Eosinophilic airway inflammation and exacerbations of COPD: a randomised controlled trial. Eur Respir J 2007;29:906-13.

4. Singh D, Kolsum U, Brightling CE, et al. Eosinophilic inflammation in COPD: prevalence and clinical characteristics. Eur Respir J 2014;44:1697-700.

5. Brightling CE, McKenna S, Hargadon B, et al. Sputum eosinophilia and the short term response to inhaled mometasone in chronic obstructive pulmonary disease. Thorax 2005;60:193-8.

6. Brightling CE, Monteiro W, Ward R, et al. Sputum eosinophilia and short-term response to prednisolone in chronic obstructive pulmonary disease: a randomised controlled trial. Lancet 2000;356:1480-5.

7. Pizzichini E, Pizzichini MM, Gibson P, et al. Sputum eosinophilia predicts benefit from prednisone in smokers with chronic obstructive bronchitis. Am J Respir Crit Care Med 1998;158:1511-7.

8. Bafadhel M, McKenna S, Terry S, et al. Blood eosinophils to direct corticosteroid treatment of exacerbations of chronic obstructive pulmonary disease: a randomized placebo-controlled trial. Am J Respir Crit Care Med 2012;186:48-55.

9. Hospers JJ, Rijcken B, Schouten JP, et al. Eosinophilia and positive skin tests predict cardiovascular mortality in a general population sample followed for 30 years. Am J Epidemiol 1999;150:482-91.

10. Hospers JJ, Schouten JP, Weiss ST, et al. Eosinophilia is associated with increased all-cause mortality after a follow-up of 30 years in a general population sample. Epidemiology 2000;11:261-8.

11. Global Strategy for the Diagnosis, Management and Prevention of COPD [homepage on the Internet]. Global Initiative for Chronic Obstructive Lung Disease (GOLD); 2017. Available online: http://goldcopd.org. Accessed June 16, 2017.

12. Roufosse F, Weller PF. Practical approach to the patient with hypereosinophilia. J Allergy Clin Immunol 2010;126:39-44.

13. Global Initiative for Asthma. Global Strategy for Asthma Management and Prevention, 2017. Available online: www. ginasthma.org

14. Ngamjarus C, Chongsuvivatwong V, McNeil E. n4Studies: Sample size calculation for an epidemiological study on a smart device. Siriraj Med J 2016;68:160-70. 
15. Vedel-Krogh S, Nielsen SF, Lange P, et al. Blood Eosinophils and Exacerbations in Chronic Obstructive Pulmonary Disease. The Copenhagen General Population Study. Am J Respir Crit Care Med 2016;193:965-74.

16. Yun JH, Lamb A, Chase R, et al. Blood eosinophil count thresholds and exacerbations in patients with chronic obstructive pulmonary disease. J Allergy Clin Immunol 2018;141:2037-47.

17. Nuchprayoon S, Siriyasatien P, Kraivichian K, et al. Prevalence of parasitic infections among Thai patients at the King Chulalongkorn Memorial Hospital, Bangkok, Thailand. J Med Assoc Thai 2002;85 Suppl 1:S415-23.

18. Tippawangkosol P, Jitpakdi A, Riyong D, et al. Incidence of parasitic infections of in- and outpatients at Maharaj

Cite this article as: Juthong S, Kaenmuang P. Association between blood eosinophils with exacerbation and patientreported outcomes in chronic obstructive pulmonary disease patients in an endemic area for parasitic infections: a prospective study. J Thorac Dis 2020;12(9):4868-4876. doi: 10.21037/jtd-194101
Nakorn Chiang Mai hospital, Chiang Mai University, Thailand 2012-2016. Chiang Mai Medical Journal 2019;58:69-76.

19. Ho J, He W, Chan MTV, et al. Eosinophilia and clinical outcome of chronic obstructive pulmonary disease: a metaanalysis. Sci Rep 2017;7:13451.

20. Couillard S, Larivée P, Courteau J, et al. Eosinophils in COPD Exacerbations Are Associated With Increased Readmissions. Chest 2017;151:366-73.

21. Barnes N, Ishii T, Hizawa N, et al. The distribution of blood eosinophil levels in a Japanese COPD clinical trial database and in the rest of the world. Int J Chron Obstruct Pulmon Dis 2018;13:433-40. 